\title{
Leaf Extracts of Lobelia nicotianaefolia as a Potential Biopesticide Against Defoliator Pests
}

\author{
B. Deepa ${ }^{*}$ and O.K. Remadevi ${ }^{2}$ \\ ${ }^{1}$ Forest and Wood protection Division, Institute of Wood Science and Technology, Bengaluru, India \\ ${ }^{2}$ Environmental Management and Policy Research Institute (EMPRI), Doresanipalya Forest Campus, \\ Bengaluru, India
}

Date Received: 10-11-2015 Date Accepted: 30-11-2015

\begin{abstract}
The environmental concern and global demand for organically produced products provide an impetus to search for new, effective, safe and economical pesticidal formulations. Plants provide enormous scope for development into pesticides. Though more than 2000 plants are known to possess insecticidal properties, neem is the only established botanical pesticide. Hence in this study, we tested the insecticidal activities of the organic solvent extracts from the leaves of L. nicotianaefolia against the larval and egg stages of a serious defoliator pest, Hyblaea puera as the test insect. The organic solvent extracts of the leaf of L. nicotianaefolia were evaluated for their contact and feeding toxicity. The larvicidal action by contact toxicity on $3^{\text {rd }}$ instar larvae of $H$. puera showed $100 \%$ mortality at $25 \%$ concentration. The ovicidal activity varied among the different extracts. All the treatments did not show any activity and were on par with control except ethyl acetate and water extracts and exhibited highest egg hatch inhibition $(80 \%)$ and $(64 \%)$ respectively at highest concentration $(2 \%)$. The $\mathrm{LC}_{50}$ value for ethyl acetate extract and water extract was 0.55 and 1.014 respectively was not significant $(\mathrm{P}>0.05)$ for ovicidal action. The feeding toxicity tests performed on $4^{\text {th }}$ instar larvae of $H$. puera showed that among all the extracts of $L$. nicotianaefolia, methanol extract showed highly significant insecticidal activity with mortality of $92 \%$, followed by ethyl alcohol extract (90\%) and water extract (86\%). The study reveals that $L$. nicotianafolia has immense potential to be explored as botanical pesticide.
\end{abstract}

Keywords: Lobelia nicotianaefolia, Hyblaea puera, larvicidal, ovicidal, botanical pesticide

\section{Introduction}

Lobelia nicotianaefolia Roth ex Roem. \& Schult. is commonly known as Indian tobacco, wild tobacco, asthma weed, vomit root, gag root, pulse weed, emetic herb and bladder pod. In India, it is distributed along the Western Ghats and is also found in Deccan and Konkan at altitudes of 900-2,100 $\mathrm{m}$. L. nicotianaefolia is an annual shrub which grows to a height of upto 1.2-3.6 m. Leaves and flowering tops of the plant is a rich source of alkaloids of the lobeline group. The whole plant, when dry, develops small spots of resinous exudation, which is hot and acrid. Leaves and aerial parts of the plant exude white latex which causes dermatitis. Seeds contain a narcotic poison and are commonly used for insect and scorpion bites. According to Nayar et al. (1979) the leaf infusion of L. excelsa is

\footnotetext{
*Correspondence: deepa_balan2002@rediffmail.com

Tel: +919448803195

ISSN 2235-9370 Print/ISSN 2235-9362 Online ㄷ University of Sri Jayewardenepura
} 
effective against aphids on snakegourd and cowpea, tingid bugs on brinjal and mites on castor and lady's finger. Jayadevi et al. (2003) studied the effect of cold and hot water extracts of $L$. nicotianaefolia leaf against, Plutella xylostella. Ovicidal properties of the hot water extract of the leaves of L. nicotianaefolia were studied by Javaregowda and Krishna Naik (2007). In this study, we tested the insecticidal activities of the organic solvent extracts from the leaves of L. nicotianaefolia against the larval and egg stages of a serious defoliator pest, Hyblaea puera as the test insect.

\section{Methodology}

The test insect, H. puera Cramer (Lepidoptera: Hyblaeidae) is the most important defoliator pest of teak in India, causing serious damage to teak trees. H. puera infestations usually occur in teak plantations almost every year mainly during the early flushing period of teak. Various teak plantations in and around Karnataka (Devanahally, Gottipura, Nellal, Nagarahole range of Rajiv Gandhi National Park, Yelwal, Gundiya, Shibaje) and Kerala (Nilambur) in India were visited during the course of study to collect the pupae of $H$. puera. The insect culture was maintained following the methodology of Nair et al. (1998). The pupae were brought to the laboratory and maintained in glass bottles covered with muslin cloth. The emerging adults were kept in cages overnight and then kept as pairs in separate glass bottles for mating. They were provided with $10 \%$ honey solution for feeding. The adults usually mated on the first or second day of emergence and started laying eggs from the third night onwards. The eggs were laid on the cloth covering the bottles. The eggs were washed in $0.5 \%$ sodium hypochlorite solution for 10 minutes. After air-drying, the eggs were kept for emergence in glass bottles along with freshly collected tender teak leaves, sprayed with $0.5 \%$ sodium hypochlorite and air-dried. The larvae were kept in glass bottles along with fresh leaves and covered with muslin cloth. In each glass bottle 20-40 larvae were kept depending upon the instar. On moulting, larvae were changed to fresh bottles. On pupation, the pupae were removed and transferred to sterilised glass bottles. Insect culture was maintained in the laboratory at $28^{\circ} \mathrm{C}$ and $16 \mathrm{~L}: 8 \mathrm{D}$ photoperiod and at $85 \%$ humidity. To maintain hygienic conditions the entire culture area was often sterilized with $70 \%$ alcohol. The glassware's were sterilized with formalin after each wash.

\subsection{Preparation of crude extract}

The leaf samples of L. nicotianaefolia were collected from Karnataka (Shampaje and Madikere forests and in and around Ponnampet) in India. The leaves were cleaned and shade dried. The dried plant material was powdered in a mixer. $100 \mathrm{~g}$ of the plant material was dissolved in $250 \mathrm{ml}$ of each of the solvent namely petroleum ether, chloroform, methanol, ethyl alcohol, ethyl acetate, acetone and water and kept for 48 hours in sealed round bottom flasks. After 48 hours, it was extracted in soxhlet apparatus until the eluting solvent turned colour less. The solvent was evaporated using rotary evaporator and the dry crude extract obtained was weighed and stored in refrigerator.

\subsection{Preparation of the test concentrations}

A known amount of crude extract obtained from the above process was dissolved in respective solvent in 1:1 proportion and serially diluted with water to obtain the desired concentrations of $0.25 \%$, $0.5 \%, 1 \%, 2 \%$ and $4 \%$. One drop of emulsifier (0.005\%) (Tween 20, Sigma Chemical Company) was added to the extract to ensure complete dispersion of the active ingredient.

\subsection{Contact toxicity with crude extract}

To evaluate the contact toxicity effects of crude extracts of L. nicotianaefolia leaf, two bioassays namely, larvicidal action and ovicidal action were conducted. 


\subsection{Larvicidal action with crude extract}

For bioassays to evaluate larvicidal action of crude extracts early $3^{\text {rd }}$ instar larvae of $H$. puera of uniform age and weight range $(9-13 \mathrm{mg})$ obtained from laboratory culture were used. Contact toxicity was tested with $0.25 \%, 0.5 \%, 1 \%, 2 \%$ and $4 \%$ concentrations. Five replications with 10 individuals each were used for each concentration. Larvae were introduced into sterilised plastic petri plates. The test solutions were applied on larvae, as topical spray using a TLC (Thin Layer Chromatography) sprayer. The petri plates were covered with the lid. In blank group the larvae were sprayed with water and in the control group the larvae were sprayed with respective solvent. The group of larvae treated with the emulsifier tween 20 also served as control. Observations were made on the behaviour of the larvae and mortality was observed at hourly intervals.

\subsection{Ovicidal action}

12-hour-old eggs were carefully taken on a small piece of muslin cloth using fine camel hair brush. Five replications with 5 eggs each were used for the experiment. The extract was prepared at a concentration of $2 \%, 1 \%$ and $0.5 \%$. It was sprayed on the egg using a micropipette. The cloth with the eggs after complete drying was introduced into glass vials and covered with muslin cloth. Treatment with water and respective solvents were served as control. The eggs were observed for hatching after 48 hours.

\subsection{Feeding toxicity of L. nicotianaefolia}

Early $4^{\text {th }}$ instar larvae of $H$. puera of uniform age and weight range $(36-45 \mathrm{mg}$ ) obtained from laboratory culture was used for bioassay. Leaf discs of $1.5 \times 1.5 \mathrm{~cm}$ size were prepared from freshly collected tender teak leaves. The leaf discs were dipped in the test solution and were placed in the sterilized plastic rearing tube. When the test solution was dried up, test larvae were transferred individually to each tube and allowed to feed for a set period of 3-5 hours. The concentrations used were $0.25 \%, 0.5 \%, 1 \%, 2 \%$ and $4 \%$. In the blank group, leaf discs were treated with water and in the control group the discs were treated with solvent. The larvae which have completely fed on the disc alone were transferred into rearing bottles provided with fresh teak leaves. The larvae, which have not fed the leaf discs completely, were discarded. Five replications with 10 individuals were used for each concentration. Mortality was recorded after 6 hours, 12 hours, 24 hours and 48 hours.

\subsection{Statistical Analysis of the data}

Percentage of larval mortality was calculated. The data was subjected to analysis of variance (ANOVA) and the means separated using least significant difference (LSD). LC 50 (lethal concentration) values were calculated using probit analysis according to calculations outlined in Finney (1971). Probit analysis was carried out using SPSS Software program version 12 and ANOVA was done with AGRES statistical package.

\section{Results}

\subsection{Bioassay for contact toxicity}

Larvicidal action

The larvicidal activity of the leaf of L. nicotianaefolia against the $3^{\text {rd }}$ instar larvae of $H$. puera did not vary among the different extracts. All the treatments were significantly different from the control. The larvae showed restless movement on spraying, and then became inactive and finally succumbed to the test solutions within 2-6 hours of spraying. The dead larvae became distorted and the body wall was later broken and the liquefied body contents oozed out. All the extracts were highly effective causing $100 \%$ mortality even with least concentration $(0.25 \%)$. 


\section{Ovicidal action}

The ovicidal activity varied among the different extracts. All the treatments did not show any activity and were on par with control except ethyl acetate and water extracts and exhibited highest egg hatch inhibition (80\%) and (64\%) respectively at highest concentration (2\%) (Table 1). The least LC $\mathrm{L}_{50}$ $(0.55 \%)$ shows that ethyl acetate extract is better than water extract (1.014\%) (Table 2). A black spot was present on the dead eggs.

Table 1: Ovicidal activity of various extracts of L. bnicotianaefolia.

\begin{tabular}{lcccc}
\hline Treatment & \multicolumn{4}{c}{ Concentration $(\%)$} \\
\cline { 2 - 4 } & \multicolumn{2}{c}{2.0} & \multicolumn{4}{c}{1.0} & 0.5 \\
\hline Ethyl acetate & $80.00 \pm 20.00(63.44)^{\mathrm{a}}$ & $64.00 \pm 32.86(53.13)^{\mathrm{b}}$ & $48.00 \pm 36.33(43.85)^{\mathrm{c}}$ \\
Water & $64.00 \pm 41.95(63.44)^{\mathrm{b}}$ & $44.00 \pm 45.60(41.55)^{\mathrm{c}}$ & $24.00 \pm 43.35(29.33)^{\mathrm{d}}$ \\
Control & $0.00(0.00)$ & & $0.00(0.00)$ & $0.00(0.00)$ \\
\hline & $\mathrm{SED}$ & $\mathrm{CD}(0.05)$ & $\mathrm{CD}(0.01)$ & \\
Treatment & 0.698 & 1.439 & 1.962 & \\
Concentration & 0.854 & 1.763 & 2.403 & \\
$\mathrm{~T}^{*} \mathrm{C}$ & 1.208 & 2.494 & 3.398 &
\end{tabular}

Mean \pm SD represents mean percentage mortality of 5 replicates with 5 individuals each. Means followed by the same alphabet does not differ significantly at $5 \%$ level of significance. Values within parentheses are angular transformed values.

Table 2: Dose - mortality response of the eggs of H. puera on contact toxicity with L. nicotianaefolia.

\begin{tabular}{lcccc}
\hline Treatment & LC50 & Slope \pm SE & Slope \pm SE & Chi-square \\
\hline Ethyl acetate extract & 0.550 & $1.48 \pm 0.63$ & $0.38 \pm 0.15$ & 0.014 \\
Water extract & 1.014 & $2.56 \pm 0.66$ & $-0.02 \pm 0.16$ & 0.466 \\
\hline
\end{tabular}

Chi-square value is less than $3.841(\mathrm{Df}=1)$ is not significant $(\mathrm{P}>0.05)$.

Feeding toxicity

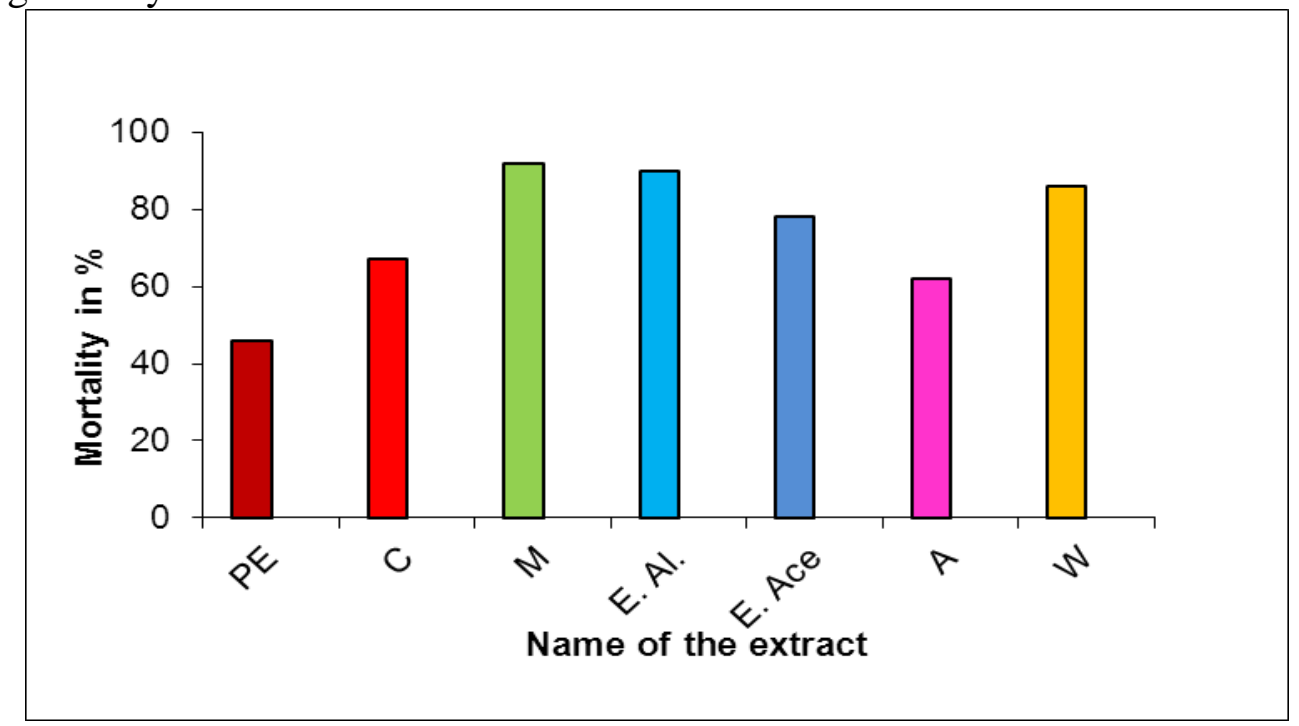

Figure 1: Feeding toxicity of various extracts of L. nicotianaefolia and E. indica on the $4^{\text {th }}$ instar larvae of $H$. puera

[PE-Petroleum ether extract, C-Chloroform extract, M-Methanol extract, E. Al-Ethyl alcohol extract, E. ace-Ethyl acetate extract, A-Acetone extract, W-Water extract] 
Based on the potency of L. nicotianaefolia, feeding toxicity tests were performed on $4^{\text {th }}$ instar larvae of $H$. puera with petroleum ether, chloroform, methanol, ethyl alcohol, ethyl acetate, acetone and water extracts. The result showed that among all the extracts of L. nicotianaefolia, methanol extract showed highly significant insecticidal activity with mortality of $92 \%$, followed by ethyl alcohol extract $(90 \%)$ and water $(86 \%)$. Petroleum ether extract was least effective (46\%) (Figure 1).

\section{Discussion}

The larvicidal activity of the leaf extracts of $L$. nicotianaefolia against the $3^{\text {rd }}$ instar larvae of $H$. puera were highly effective causing $100 \%$ mortality even with least concentration $(0.25 \%)$. Jayadevi et al. (2003) reported that the cold and hot water extracts of L. nicotianaefolia leaf against Plutella xylostella, to be less effective. Lobelia excelsa has produced effective control of major pests of cabbage at a concentration of $500 \mathrm{ml} \mathrm{ha}^{-1}$ and has been said to be on par with monocrotophos $(0.05 \%)$ (Rajavel and Veeraraghavathatham, 1989) which is in agreement with our finding. L. nicotianaefolia is used by rural communities against insect pests. This plant has rapid knockdown effect similar to that of pyrethrins. The symptoms of death like hyperactivity and convulsions are also as that of pyrethrins, which have neurotoxic action, which block voltage - gated sodium channels in nerve axons (Isman, 2006). Contact insecticides can kill small insects through suffocation by blocking the spiracles or disruption of cuticular waxes and membranes in the integument leading to desiccation (Isman, 2006). Moreover, the test insect Hyblaea puera is a forest pest and hence it is more sensitive. The $3^{\text {rd }}$ instar larval stages of $H$. puera used in the experiment possess soft body which also would have attributed to its rapid mortality at $0.25 \%$ concentration.

All the treatments did not show any ovicidal activity and were on par with control except ethyl acetate and water extracts and exhibited highest egg hatch inhibition (80\%) and (64\%) respectively at highest concentration (2\%). The study shows that $L$. nicotianaefolia is not only a larvicide but also an effective ovicide which disagrees with the findings of Javaregowda and Krishna Naik (2007). The low egg hatch inhibition at $2.5 \%$ in their study may because of the use of water extract. It is possible that these plant extracts may have one or more chemical substances, which may block the micropyle region of the egg thereby preventing the exchange of gases ultimately killing the embryo in the egg itself. Enslee and Riddiford (1977) reported that ovicidal activity is due to unequal penetration of extracts through the egg chorion to different parts of egg. Similar findings were earlier reported in the eggs of Cnaphalocrocis medinalis (Saxena et al., 1981), S. litura and Percicallia ricini (Venkateswarlu, 1988), L. orbonalis (Srinivasan and Sundarababu, 1999). Toxic effects of neoannonin, a novel insecticidal compound isolated from the seeds of Annona squamosa to eggs, larvae and adults of Drosophila melanogaster have also been reported (Kawazu et al., 1989). The disturbance with egg cytoplasm was reflected in the form of dead eggs with black spot stage due to the arresting of further development of embryo inside the egg. Bhatnagar and Sharma (1994) and Elumalai et al. (2005) noticed similar anatomical and physiological disturbances of plant extracts on maize stem borer, Chilo partellus. Other plants like Melia azadarach, Strychnous nux vomica, Jatropha curcas, Cassia fistula, Gnidia glauca, Ricinus communis, Vitex negunda, Derris indica, Clerodendron inermae, Lantana caftera, Semecarpus kathalekanesis have been proved to produce varying degree of ovicidal activity on the eggs of H. puera (Javaregowda and Krishna Naik, 2007; Ramana, 2005, 2006a).

The result of feeding toxicity showed that among all the extracts of L. nicotianaefolia, methanol extract showed highly significant insecticidal activity with mortality of $92 \%$, followed by ethyl alcohol extract $(90 \%)$ and water $(86 \%)$. The toxicity could be assessed only at least concentration $(0.25 \%)$ as 
the larvae did not feed the leaf discs with higher concentration of the extract. It shows that at higher concentration the extracts had antifeedant activity. Our findings are in agreement with the following studies. Methanolic extracts from leaves and seeds of chinaberry tree, Melia azedarach L. tested against the larvae of $H$. puera were found to affect the growth, feeding and oviposition of $H$. puera in the laboratory condition (Senthil Nathan and Sehoon, 2006). Ramanna (2006b) reported 74.81\% larval mortality at $4 \%$ concentration with ethanol extract of the leaves of Semecarpus kathalekanensis on the $3^{\text {rd }}$ instar larvae of Hyblaea puera after 24 hours. Durairaj (2010) has observed $80 \%$ mortality of $H$. puera larvae within a short period of 24 hours at $2 \%$ concentration. His study also reported $60 \%$ mortality recorded with $1 \%$ Oscimum extracts within 48 hours. Senthilkumar et al. (2012) reported 100\% mortality of the larvae of $H$. puera at $1000 \mathrm{ppm}$ with methanol and ethyl acetate extract of the leaves of Melia dubia, among eight plants tested. In the present study, the symptoms of toxicity caused the rupture of the hind end of the larva and the midgut oozed out along with body fluid, when the larvae consumed the leaf disc treated with the extract of $L$. nicotianaefolia leaf. This shows that the leaf extract of L. nicotianaefolia is highly toxic.

\section{Conclusion}

The results show that Lobelia nicotianaefolia has immense potential as insecticide. Further work is in progress to use them in bio-pesticide formulation.

\section{Acknowledgement}

Authors are grateful to Institute of Wood Science and Technology, India for the facilities provided and Kerala Forest Research Institute, India for helping in bioassays. The first author is grateful to University Grants Commission, India for the financial assistance.

\section{References}

Bhatnagar, A. and Sharma, V.K. 1994. Insecticidal and ovicidal activities of plant extracts against maize stem borer, Chilo partellus (Swinhoe). Plant Protect Bulletin 46: 12-16.

Durairaj, S. 2010. Screening of biopesticidal properties of Oscimum tenuiflorum L. and Parthenium hysterophorus L. against Hyblaea puera Cramer (Hyblaeidae: Lepidoptera). Current Biotica, 4(1): 116-120.

Elumalai, K., Jeyasankar, A., Jayakumar, M., Raja, N. and Ignacimuthu, S. 2005. Isolated fractions of Hyptis suaveolens and Melochia chorcorifolia against the gram pod borer Helicoverpa armigera (Hubner), In: S.J. Ignacimuthu, Jayaraj, S. (eds.), Sustainable insect pest management, Narosa Publishing House, New Delhi, India, 181-187 pp.

Enslee, E.C. and Riddiford, L.M. 1977. Morphological effects of JKM on embryonic development in the bug Pyrrhocoris apteru. Wilhelm Roux's Archives of Developmental Biology, 181: 163181.

Isman, M.B. 2006. Botanical insecticides, deterrents and repellents in modern agriculture and an increasingly regulated world. Annual Review of Entomology, 51: 45-66.

Javaregowda, and Krishana Naik, L. 2007. Ovicidal properties of plant extracts against the eggs of teak defoliator, Hyblaea puera Cramer. Karnataka Journal of Agricultural Sciences, 20(2): 291293.

Jayadevi, H.C., Sumithramma, N., Nagaraj, N. and Kumar, A.R.V. 2003. Field evaluation of aqueous extracts of Gnidia gluaca and Lobelia nicotianaefolia leaves for the management of Diamondback moth in cabbage. Pest Management in Horticultural Ecosystems, (9)1: 41-47. 
Kawazu, K., Alcantara, J. and Kobayashi, A. 1989. Isolation and structure of neoannonin, a novel insecticide compound from seeds of Annona squamosa. Agricultural and Biological Chemistry, 53: 2719-2722.

Nair, K.S.S., Sudheendrakumar, V.V., Varma, R.V. and Chacko, K.C.1985. Studies on the seasonal incidence of defoliators and the effect of defoliators on volume increment of teak. Research Report, Kerala Forest Research Institute, pp. 30-78.

Nayar, K. K., Ananthakrishnan, T.N. and David, B.V. 1979. General and applied entomology. Tata McGraw-Hill Publishing Company Ltd., New Delhi.

Rajavel, S.D. and Veeraraghavathatham, D. 1989. Efficacy of certain plant extracts on the major pests of cabbage. South Indian Horticulture, 37(3): 186-188.

Ramana, P. 2005. Ovicidal evaluation of Chromolaena odorata extracts on teak defoliator-Hyblaea puera Cramer. My forest, 41(4): 519-524.

Ramana, P. 2006a. Ovicidal evaluation of Semecarpus kathalekanensis extracts on teak defoliator, Hyblaea puera cramer. Journal of Non-Timber Forest Products, 13(4): 245-248.

Ramanna, P. 2006b. Larvicidal activity of Semecarpus kathalekanensis extracts against teak defoliator, Hyblaea puera Cramer. My Forest, 42(3): 301-305.

Saxena, R.C., Waldbauer, G., Liguido, N.J. and Puma, B.C. 1981. Effects of neem seeds oil on the rice leaf folder Cnaphalocrocis medanlis, $1^{\text {st }}$ International Neem Conference, Rottach Egern. 189-204.

Senthil Nathan S. and Sehoon, K. 2006. Effects of Melia azedarach L. extract on the teak defoliator Hyblaea puera cramer (Lepidoptera: Hyblaeidae). Crop Protection, 25: 287-291.

Senthilkumar, N., Murugesan, S., Vijayalakshmi, K.B., Monisha, M., Suresh Babu, D., Lakshmidevi, R. and Manivachakam, P. 2012. Insecticidal properties of certain flora based on ethnobotanical records against teak defloaitor, H. puera Cramer (Lepidoptera: Hyblaeidae). European Journal of Experimental Biology, 2(3): 513-519.

Srinivasan, G. and Sundarababu, P. 1999. Ovicidal and ovipositional deterrent effect of neem products on brinjal shoot and fruit borer, Lucinodes arbonalis Guenee (Lepidoptera: Pyralidae), In S. Ignacimuthu, A. Sen. (eds.), Biopesticides in insect pest management. Phoenix Publishing House, New Delhi, India, 56-58 pp.

Venkateshwarlu, P., Raghavaiah, G. and Nagalingam, P. 1988. Effect of neem oil on behavioural aspects of S. litura F. Indian Journal of Pulses Research, 1: 118-123. 